\title{
Eye Tracking e Fonoaudiologia: teoria e práticas atuais
}

\author{
Comentado por: Talita Fortunato-Tavares ${ }^{1}$
}

Duchowski AT. Eye tracking methodology. 2nd ed. New York: Springer; 2007.

$\mathrm{O}$ uso de metodologias de pesquisa online (processuais) tem sido um recente e importante foco de pesquisa nos mais renomados centros de pesquisa internacionais. Com o avanço da Fonoaudiologia como ciência, cresce também, na área, o número de estudos que analisam não somente a resposta comportamental final do participante, mas também todo o processo o qual levou o participante àquela decisão.

Uma dessas tecnologias em grande evolução e crescimento em uso é o Eye Tracker. Esta ferramenta se tornou, com o recente avanço tecnológico, um aplicável método de monitoramento do movimento ocular de acordo com estímulos apresentados. Basicamente, os aparelhos de Eye Tracking gravam os movimentos que o "olhar" do participante realizou enquanto determinados estímulos auditivos e/ou visuais foram apresentados. Os mais modernos aparelhos disponíveis analisam os movimentos oculares através de leitores infravermelhos que medem os movimentos relativos da córnea e pupila por complexas metodologias Física e Computacional.

Atualmente em sua quarta geração, os equipamentos de Eye Tracking sofreram uma importante evolução desde os primeiros indícios de análise objetiva de movimentos oculares usando reflexo de córnea em 1901. Nos anos 50, foram desenvolvidos equipamentos anexados a lentes de contato, os quais poderiam ser desde pequenos espelhos até grandes estruturas de ferro. Esse método, até então, se apresentava muito invasivo e pouco prático. Já os modelos pertencentes à terceira geração, os quais eram utilizados até recentemente, eram desconfortáveis estruturas com armações presas na cabeça, similares a capacetes (head mounted), e impediam a movimentação do participante, sendo que este, normalmente, teria que permanecer com o queixo fixado a uma estrutura de metal para evitar sua movimentação e, conseqüentemente, perda dos dados. Hoje, os modernos equipamentos da quarta geração são os chamados "de mesa" (table mounted) e têm a aparência de um monitor de computador do tipo "LCD". Esses equipamentos modernos são nada invasivos, muito mais precisos, e apresentam grande praticidade para aplicações em pesquisas com crianças tão novas quanto seis meses de idade já que não há estruturas anexadas ao participante.

Esses equipamentos disponíveis atualmente são capazes de medir a uma frequiência de até $60 \mathrm{~Hz}$ (a cada segundo, o

(1) Post graduate student of the PhD Program in Speech, Language and Hearing Sciences, The Graduate Center, The City University of New York CUNY - New York (NY), USA.

Endereço para correspondência: Talita Fortunato-Tavares. Ph.D. Program in Speech, Language and Hearing Sciences. City University of New York Graduate School and University Center - 365 Fifth Avenue, Room 7410, New York - NY, 10016-4309, USA. E-mail: tfortunato@gc.cuny.edu equipamento grava até 60 coordenadas, ou seja, a cada segundo o Eye Tracker obtém dados de 60 posições para as quais o participante dirigiu seu olhar). Com alta precisão e rapidez, o Eye Tracker fornece informação automática de onde o interesse do participante está focado.

Os dados fornecidos pelo Eye Tracker são também de um grande espectro que varia, dependendo do objetivo da pesquisa, em: tempo total de fixação em uma determinada área da tela, ordem de fixação, velocidade de cada fixação, número de transições, entre outros. Outra importante função é sua capacidade de apresentar um retorno em tempo real dos movimentos visuais realizados o que, além de engajar o participante, pode servir como direcionamento para diferentes níveis, dependendo do design da pesquisa.

Devido a toda essa evolução, o número de estudos relacionados à Fonoaudiologia que utilizam equipamentos de Eye Tracking encontra-se em crescimento atualmente. A aplicabilidade dos equipamentos de Eye Tracking em Fonoaudiologia tem se ampliado devido também à maior flexibilidade metodológica e tecnológica, que possibilita uma maior acessibilidade aos pesquisadores.

Atualmente, a aplicabilidade do Eye Tracking em Fonoaudiologia tem sido direcionada em um âmbito vasto de suas áreas. Yee e Sevidy utilizaram o Eye Tracking para analisar a ativação semântica transiente durante o reconhecimento de vocábulos falados mensuradas através dos movimentos oculares produzidos pelos participantes ${ }^{(1)}$. Como um exemplo de aplicabilidade do Eye Tracking em estudo de sintaxe, Fortunato-Tavares et al. utilizaram movimentos oculares para testar a hipótese de Déficit em Ordenação de Hierarquia de crianças com Distúrbio Específico de Linguagem ${ }^{(2)}$. Estudos sobre leitura e escrita também têm sido conduzidos. Justice et al., em 2005, utilizaram a análise de movimentação ocular para verificar a interferência de diversos tipos de figuras e texto na compreensão de livros em pré-escolares ${ }^{(3)}$. Neste último, assim como nos demais estudos brevemente descritos acima, dados providos pelo Eye Tracker forneceram informações cruciais sobre processamento que não poderiam ter sido observadas somente pela resposta comportamental. Diversas outras áreas aplicadas à Fonoaudiologia também têm se beneficiado do uso de Eye Trackers como, por exemplo, processamento de acentos de pitch $^{(4)}$, processamento de frases ${ }^{(5)}$, pronomes e sintaxe em geral $^{(6-7)}$.

Entretanto, como se trata de uma tecnologia complexa e com aplicabilidade relativamente recente, não são muitas as fontes de informações que podem ser encontradas sobre sua metodologia. Apesar do crescente número de laboratórios de universidades que utilizam a tecnologia e o conseqüente 
aumento no número de publicações referentes ao tema, ainda não há muitas fontes de informações disponíveis em como desenvolver, implementar e analisar os dados fornecidos por este sistema.

O livro entitulado Eye Tracking Methodology, escrito por Andrew T. Duchowski em 2007 é uma importante e densa referência sobre a metodologia de Eye Tracking. Este livro faz um tratamento abrangente do uso do campo visual como instrumento de pesquisa. Em sua segunda edição, o livro reúne teoria, conhecimento prático e aplicações no "mundo real" de uma maneira compreensível e informativa. O livro de Duchowski é dividido em quatro partes seguindo um estilo top down. Primeiramente fornece uma introdução ao sistema de visão humano, seguido de um breve histórico dos sistemas de Eye Tracking, passando, na terceira parte a discutir sobre sua metodologia em geral e, por fim, apresenta uma revisão de suas várias possíveis aplicações.

Apesar do crescimento do uso do Eye Tracker na pesquisa internacional em Fonoaudiologia, o custo desses equipamentos e dos softwares necessários para calibração, coleta e análise de dados apresenta-se ainda relativamente elevado. Porém, o rápido avanço tecnológico também traz vantagens no âmbito financeiro, já que esses custos para o consumidor final têm decrescido ultimamente. Este fato também deverá fazer com que a utilização e a valorização dessa importante ferramenta de pesquisa seja expandida, possibilitando uma verificação e mensuração bem mais objetiva e precisa de dados, contribuindo, ainda mais, para um maior desenvolvimento da Fonoaudiologia como ciência.

\section{REFERENCIAS}

1. Yee E, Sedivy, J. Eye Movements to Pictures Reveal Transient Semantic Activation During Spoken Word Recognition. J Exp Psychol Learn Mem Cogn. 2006;32(1):1-14.

2. Fortunato-Tavares T, Hestvik A, Tropper B, Schwartz, RG. Eye tracking studies of structural assignment in children with specific language impairment. Seminar presented at the American Speech and Hearing Association Conference, Chicago, IL. November; 2008.

3. Justice L, Skibbe L, Canning A, Lankford C. Pre-schoolers, print and storybooks: an observational study using eye movement analysis. J Res Read. 2005;28(3):229-43.
4. Watson D, Tanenhaus M, Gunlogson C. Interpreting pitch accents in online comprehension: H* vs. L+H*. Cogn Sci. 2008;32(7):1232-44.

5. Mitchell D, Shen X, Green M, Hodgson T. Accounting for regressive eye-movements in models of sentence processing: A reappraisal of the Selective Reanalysis hypothesis. J Mem Lang. 2008;59(3):266-93.

6. Kaiser E, Trueswell J. Interpreting pronouns and demonstratives in Finnish: Evidence for a form-specific approach to reference resolution. Lang Cogn Process. 2008;23(5):709-48.

7. Traxler M, Tooley K. Priming in sentence comprehension: Strategic or syntactic?. Lang Cogn Process. 2008;23(5):609-45. 